\title{
An evaluation of two aerosol delivery systems for rhDNase
}

\author{
P.L. Shah*, S.F. Scott*, D.M. Geddes*, S. Conway**, A. Watson**, T. Nazir ${ }^{+}$, \\ S.B. Carr ${ }^{++}$, C. Wallis ${ }^{++}$, C. Marriott ${ }^{+}$, M.E. Hodson*
}

\begin{abstract}
An evaluation of two aerosol delivery systems for rhDNase. P.L. Shah, S.F. Scott, D.M. Geddes, S. Conway, A. Watson, T. Nazir, S.B. Carr, C. Wallis, C. Marriott, M.E. Hodson. (C)ERS Journals Ltd 1997.

ABSTRACT: Increasingly, proteins are delivered to the respiratory tract as an aerosol, and clinical efficacy is dependent on optimal delivery of the protein in an intact form. The object of this study was to compare the in vivo and in vitro results of two aerosol delivery systems for the aerosolization of recombinant human deoxyribonuclease I (rhDNase) in patients with cystic fibrosis (CF).

Patients with CF who were to be initiated on rhDNase were randomized either to the Hudson nebulizer and Pulmo-Aide compressor or to the Sidestream nebulizer driven by the CR50 air compressor. An in vitro study was performed in six sets of the two aerosol delivery systems. One hundred and seventy three patients were randomized in this open study, where rhDNase was administered for 7 days.

Improvements in pulmonary function were observed in both groups following 1 week of therapy with rhDNase. Changes in the Sidestream/CR50 and Hudson/ Pulmo-Aide groups, respectively, were: 16 and $11 \%$ for forced expiratory volume in one second $(p=0.14) ; 12$ and $10 \%$ for forced vital capacity $(p=0.70)$; and 14 and 7\% for forced expiratory flow at 25-75\% of expiration (FEF25-75) $(p=0.18)$. A greater proportion of patients in the Sidestream/CR50 group (58\%) had a $>10 \%$ response in FEF 25-75 compared to the Hudson/Pulmo-Aide group $(42 \% ; p=0.03)$. The Sidestream nebulizer had a faster nebulization rate $(\mathbf{p}<0.05)$, lower mass median diameter for the aerosol mass produced $(p<0.001)$, higher percentage of particles in the respirable range $(p<0.001)$ and greater respirable output $(p<0.005)$, compared to the Hudson nebulizer.

The Sidestream/CR50 combination is a quicker, more efficient system in vitro than the Hudson/Pulmo-Aide combination, whereas the in vivo study only suggested a difference. Clinically, the two systems have similar efficacy.
\end{abstract}

Eur Respir J 1997; 10: 1261-1266.

\begin{abstract}
*Dept of Cystic Fibrosis, Royal Brompton Hospital and National Heart \& Lung Institute, Imperial College, London, UK. **Regional Adult Cystic Fibrosis Unit, Seacroft Hospital, Leeds, UK. +Dept of Pharmacy, King's College London, London, UK. ${ }^{++}$Great Ormond Street Hospital for Children, London, UK.
\end{abstract}

\section{Correspondence: M.E. Hodson}

Royal Brompton Hospital

Sydney Street

London SW3 6NP

UK

Keywords: Cystic fibrosis

jet nebulizers

recombinant human deoxyribonuclease

Received: October 241996

Accepted after revision February 281997
Accumulation of purulent infected sputum in the respiratory tract of patients with cystic fibrosis $(\mathrm{CF})$ obstructs airways and causes chronic symptomatic infection [1]. Sputum in CF is rich in leucocyte-derived extracellular deoxyribonucleic acid (DNA), which contributes to the abnormal rheology of the airway secretions [2-4]. Recombinant human deoxyribonuclease I (rhDNase) reduces the viscoelasticity of CF sputum and improves pulmonary function. Short-term studies have demonstrated improvements in forced expiratory volume in one second (FEV1) between 10-15\% [5, 6]. Longer-term administration demonstrates a modest reduction in respiratory exacerbations [7], and open-label therapy has shown that improvements in FEV1 of around $6 \%$ are maintained for up to 2 yrs [8].

The previous clinical studies have used delivery systems made in the USA: the Pulmo-Aide compressor (DeVilbiss, Somerset, PA, USA) with either the Marquest Acorn II nebulizer (Marquest Medical Inc, Englewood, CO, USA) or the Hudson T-Updraft II nebulizer (Hudson, Irvine, CA, USA). The availability of the Hudson and Acorn II disposable nebulizers in the UK is limited, whereas the Sidestream nebulizer (Medic-Aid, Pagham, Sussex,
UK) driven by the CR50 compressor (Medic-Aid) is more widely-used. Jet nebulizers produce an aerosol from liquids by shearing at the air-liquid interface with a fast stream of air [9]. Proteins generally tend to behave as surface active molecules, and recirculation of protein solutions under high shear rates in the nebulizer bowl may result in the denaturation of the protein [10]. It is, therefore, important to evaluate any alternative aerosol delivery systems in vivo as well as in vitro.

\section{Methods}

In vivo study

A multicentre, parallel-arm open study was undertaken, with randomization of CF patients either to the Sidestream nebulizer with a CR50 compressor, or to the Hudson T-Updraft II nebulizer with a Pulmo-Aide compressor. All patients were to be treated with open-label rhDNase for 7 days. The protocol was approved by all of the Hospital Ethics Committees and all patients provided informed consent. 
Eligibility criteria. The diagnosis of $\mathrm{CF}$ was confirmed by a sweat sodium $\geq 70 \mathrm{mEq} \cdot \mathrm{L}^{-1}$ or, if homozygous for the $\Delta \mathrm{F} 508$ mutation, the presence of a history consistent with $\mathrm{CF}$. Patients were required to be above 5 yrs of age, with a forced vital capacity (FVC) $\geq 40 \%$ predicted at screening, and arterial oxygen saturations $\left(\mathrm{Sa}_{\mathrm{a}} \mathrm{O}_{2}\right)$ $\geq 90 \%$, and to be able to perform reproducible lung function tests. No patient had previously received rhDNase.

No change in antibiotics, bronchodilators or steroid treatment was permitted within 14 days of commencement of the study. Any patients who were hospitalized during the 14 day period prior to the study were excluded. Other exclusion criteria were pregnancy and the use of any investigational drug within 28 days prior to the start of the study.

Conduct of the study (table 1). Prospective subjects were evaluated for eligibility on two separate screening visits (7 days before and on the day of randomization). Pulmonary function tests were performed according to American Thoracic Society (ATS) guidelines [11]. Eligible patients were randomized to one of the two aerosol delivery systems. All the patients received new equipment in order to control for the quality of the equipment. The patients were given verbal and written instructions on the correct use of the nebulizer. The Sidestream nebulizers were reusable, whereas the Hudson T-Updraft nebulizers were discarded after a single use. All patients used noseclips during inhalation of rhDNase. Patients received $2.5 \mathrm{mg}$ rhDNase as $2.5 \mathrm{~mL}$ rhDNase $\left(1.0 \mathrm{mg} \cdot \mathrm{mL}^{-1}\right)$ in formulation buffer $\left(8.77 \mathrm{mg} \cdot \mathrm{mL}^{-1} \mathrm{NaCl}, 0.15 \mathrm{mg} \cdot \mathrm{mL}^{-1}\right.$ $\left.\mathrm{CaCl}_{2}, \mathrm{pH} 6.3 \pm 0.7\right)$.

Pulmonary function was re-evaluated after 7 days of treatment with rhDNase. Duration of aerosol administration, adverse events, patient hospitalizations, or changes in medication were recorded.

\section{In vitro study}

Six of the Sidestream/CR50 combinations and six of the Hudson/Pulmo-Aide delivery systems were randomly evaluated in vitro prior to dispensing to the patients. The nebulizer pressure-flow characteristics were measured by attaching an airflow meter and a Bourdon type pressure gauge via a T-connector interposed between the

Table 1. - Conduct of study

\begin{tabular}{lccc} 
& & & Study day* \\
& -7 & 1 & 8 \\
\hline Physical examination & $\times$ & & \\
Medical history & $\times$ & & \\
Demographics & $\times$ & & \\
Height/weight & $\times$ & & \\
Oximetry & $\times$ & & \\
Current secondary diagnoses & $\times$ & $\times$ & \\
Spirometry & $\times$ & $\times$ & $\times$ \\
Sputum collection & & $\times$ & $\times$ \\
Record any adverse events & $\times$ & $\times$ & $\times$ \\
Record any antibiotics & & $\times$ & \\
Randomization & & $\times$ & \\
Demonstration of correct nebulizer use & & $\times$ & \\
Time administration of aerosol & & $\times$ & $\times$ \\
Review patient log & & & $\times$ \\
Drug accountability & & \\
Dispense study medication & & \\
\hline *. 7 days before and 1 and 8 days after randomization &
\end{tabular}

*: 7 days before and 1 and 8 days after randomization. nebulizer and the compressor. Aerosol droplet size produced by the systems was measured by a Malvern Instruments 2600C laser particle and droplet analyser (Malvern Instruments, Malvern, Worcestershire, UK).

The nebulizers were fitted with their mouthpieces and clamped onto the particle sizer, with the top of the mouthpiece positioned $6 \mathrm{~cm}$ from the laser beam. The aerosol spray was directed across the laser beam using a suction pump placed opposite the mouthpiece. Particle size was derived from the laser diffraction angles, based on the "Fraunhofer" theory and the "anomalous diffraction" theory. A $63 \mathrm{~mm}$ range lens was used and the size distribution of the aerosol mass was plotted into 42 size bands from 1.2 to $258 \mu \mathrm{m}$ on a logarithmic scale. The mass median diameter and the percentage of the aerosol mass in the respirable range $(1.0-5.6 \mu \mathrm{m}$ in diameter) were calculated. Aerosol particle size was evaluated at three different time-points of nebulization (initiation, half way through, and near the end of nebulization). The nebulization time, i.e. from the start of nebulization up until no visible aerosol was produced for $15 \mathrm{~s}$, was recorded.

Aerosol output was estimated by collection onto a filter paper. A weighed $8 \mathrm{~cm}$ square piece of filter paper (medium thickness; Sigma, Poole, Dorset, UK) was placed $4 \mathrm{~cm}$ in front of the nebulizer mouthpiece. A suction pump was used to draw the aerosol onto the filter paper. The filter paper was allowed to dry in a desiccant-filled jar and the dry weight determined after $24 \mathrm{~h}$. The dry weight of the aerosol output (excipients and rhDNase) on the filter paper was calculated by subtracting the initial weight from the final weight. The nebulizer pot was weighed prior to the experiment and following nebulization placed in the desiccant jar. The dry weight of the residual was calculated and this provided a means of ensuring mass balance in the experiment, i.e. dry weight of the residual + dry weight of aerosol output $=$ dry weight of initial rhDNase solution.

Nebulizer efficiency (E) was determined by dividing the dry weight of the aerosol on the filter paper by the total dry weight of the initial $2.5 \mathrm{~mL}$ rhDNase solution. Respirable output, which is a measure of aerosol delivery at respirable specifications, was estimated from the respirable fraction (RF) and the nebulizer efficiency:

$$
\mathrm{D}=\mathrm{E} \times \mathrm{RF}
$$

However, the actual amount of rhDNase in each particle size fraction is unknown. For the purposes of our analysis, it is assumed that rhDNase and excipients distribute equally in all aerosol particles. The proportion of rhDNase to excipients in an aerosol particle should be independent of the particle size and dependent upon the concentration in the reservoir solution. With jet nebulizers, evaporation occurs due to contact of the solution with a dry air stream, and, therefore, the concentration of the solution increases during the nebulization process [9]. Other authors have shown that both rhDNase and sodium (main excipient) concentrate proportionally during nebulization [12].

\section{Statistical analysis}

Baseline pulmonary function was the mean of the two screening visits (Day -7 and Day 1). The change 
in pulmonary function before and after the treatment period was calculated as median percentage change from baseline:

$$
\frac{\text { FEV } 1 \text { day } 8-\text { baseline FEV } 1}{\text { baseline FEV } 1} \times 100
$$

The results are presented as median (with interquartile range). The significance of the percentage change from baseline between the two groups was evaluated by the Mann-Whitney U-test. Short-term response was defined as improvement in lung function by greater than $10 \%$, and the number of responders in the two groups compared by Chi-squared analysis.

The in vitro results (aerosol droplet size, output characteristics, nebulizer efficiency, and estimated respirable output) are presented as median with interquartile range. The significance of the results was evaluated by Mann-Whitney U-test. A p-value less than 0.05 was considered statistically significant.

\section{Results}

In vivo study

One hundred and seventy three patients were recruited from three centres in the UK. Eighty six patients were randomized to receive rhDNase, $2.5 \mathrm{mg}$ once daily, delivered by a sidestream nebulizer and CR50 compressor, and 87 patients by a Hudson T-Updraft nebulizer and Pulmo-Aide compressor. Baseline demographics and characteristics were similar in the two groups and are summarized in table 2.

Therapy with rhDNase appeared to be safe, with no difference in the adverse event profile in the two groups (table 3). The main adverse events observed were an increased incidence of pharyngitis voice alteration, which were consistent with the observations of previous clinical studies with rhDNase [5,7].

The changes in pulmonary function are presented in table 4. Median (interquartile range) percentage increase in FEV1 was 16 (7-25)\% in the Sidestream/CR50 group compared to 11 (4-25)\% in the Hudson/Pulmo-Aide group ( $\mathrm{p}=0.14)$. Sixty seven per cent of patients in the Sidestream/CR50 group had a $>10 \%$ improvement in

Table 2. - Baseline and demographic characteristics

\begin{tabular}{|c|c|c|}
\hline & $\begin{array}{c}\text { Sidestream/ } \\
\text { CR50 } \\
(\mathrm{n}=86)\end{array}$ & $\begin{array}{c}\text { Hudson/ } \\
\text { Pulmo-Aide } \\
(\mathrm{n}=87)\end{array}$ \\
\hline $\operatorname{Sex} \quad M / F$ & $41 / 43$ & $46 / 41$ \\
\hline Age yrs & $\begin{array}{c}24 \\
(20-30)\end{array}$ & $\begin{array}{c}25 \\
(20-30)\end{array}$ \\
\hline Baseline FEV1 L & $\begin{array}{c}1.3 \\
(1.0-2.0)\end{array}$ & $\begin{array}{c}1.5 \\
(0.9-2.1)\end{array}$ \\
\hline Baseline FEF25-75 L $\mathrm{L} \cdot \mathrm{s}^{-1}$ & $\begin{array}{c}0.6 \\
(0.4-1.1)\end{array}$ & $\begin{array}{c}0.6 \\
(0.4-1.0)\end{array}$ \\
\hline Baseline FVC L & $\begin{array}{c}2.7 \\
(2.2-3.5)\end{array}$ & $\begin{array}{c}2.7 \\
(2.0-3.6)\end{array}$ \\
\hline
\end{tabular}

Data are presented as median, with interquartile range in parenthesis. M: male; F: female; FEV1: forced expiratory volume in one second; FEF25-75: forced expiratory flow at $25-75 \%$ of expiration; FVC: forced vital capacity.
Table 3. - Adverse event profile

\begin{tabular}{lcc}
\hline Adverse event & $\begin{array}{c}\text { Sidestream/ } \\
\text { CR50 } \\
(\mathrm{n}=86)\end{array}$ & $\begin{array}{c}\text { Hudson/ } \\
\text { Pulmo-Aide } \\
(\mathrm{n}=87)\end{array}$ \\
\hline Increased dyspnoea & 1 & 1 \\
Haemoptysis & 1 & 0 \\
Pneumothorax & 0 & 0 \\
Chest pain & 0 & 0 \\
Pharyngitis & 6 & 9 \\
Voice alteration & 3 & 5 \\
Laryngitis & 1 & 0 \\
Respiratory tract exacerbation & 3 & 3 \\
Upper respiratory tract infection & 3 & 1 \\
\hline
\end{tabular}

FEV1 (58 responders out of 86) compared to $59 \%$ in the Hudson/Pulmo-Aide group ( $\mathrm{p}=0.23$ ) (fig. 1). Five patients had a decline in FEV1 in the Sidestream/CR50 group compared to 13 in the Hudson/Pulmo-Aide group. Changes in FVC were $12(5-20) \%$ in the Sidestream/CR50 group and 10 (5-22)\% in the Hudson/Pulmo-Aide group $(\mathrm{p}=0.70)$. Fifty nine per cent of the Sidestream/CR50 group were defined as responders (fig. 2) compared to $53 \%$ for the Hudson/Pulmo-Aide group $(\mathrm{p}=0.39)$. Changes in forced expiratory flow at $25-75 \%$ of expiration (FEF25-75) demonstrated greater variance, and the median change in the Sidestream/CR50 group was $14(-5-$ $28) \%$ compared to a median change of $7(-4-25) \%$ in

Table 4. - Changes $(\Delta)$ in pulmonary function from baseline

\begin{tabular}{|c|c|c|c|}
\hline & $\begin{array}{c}\text { Sidestream/ } \\
\text { CR50 } \\
(\mathrm{n}=86)\end{array}$ & $\begin{array}{c}\text { Hudson/ } \\
\text { Pulmo-Aide } \\
(\mathrm{n}=87)\end{array}$ & p-value $\#$ \\
\hline$\triangle \mathrm{FEV}_{1} \%$ & $\begin{array}{c}16 \\
(7-25)\end{array}$ & $\begin{array}{c}11 \\
(4-25)\end{array}$ & 0.14 \\
\hline$\triangle \mathrm{FEF} 25-75 \%$ & $\begin{array}{c}14 \\
(-5-28)\end{array}$ & $\begin{array}{c}7 \\
(-4-25)\end{array}$ & 0.18 \\
\hline$\Delta \mathrm{FVC} \%$ & $\begin{array}{c}12 \\
(5-20)\end{array}$ & $\begin{array}{c}10 \\
(5-22)\end{array}$ & 0.70 \\
\hline
\end{tabular}

Percentage changes are presented as median, with interquartile range in parenthesis. \#: Mann-Whitney U-test.

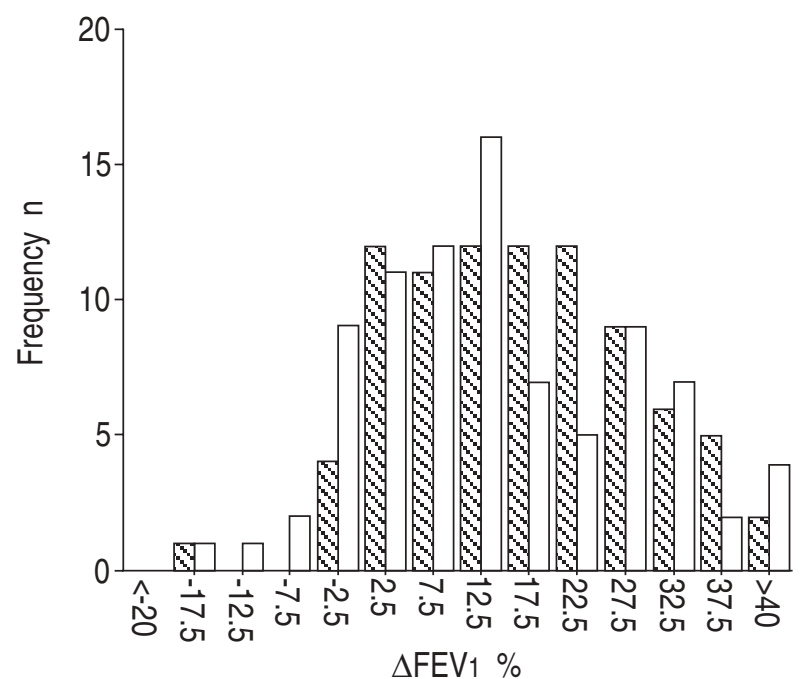

Fig. 1. - Histogram of percentage change from baseline in forced expiratory volume in one second $\left(\Delta \mathrm{FEV}_{1}\right)$ for the Sidestream/ CR50 aerosol delivery system ( $\mathrm{S}$ ) and the Hudson/Pulmo-Aide system $(\square)$. 
the Hudson/Pulmo-Aide group $(\mathrm{p}=0.18)$. The proportion of patients defined as responders was $58 \%$ for the Sidestream/CR50 group and $42 \%$ for the Hudson/PulmoAide group ( $\mathrm{p}=0.03$ ) (fig. 3). Twenty seven per cent of patients had a decline in FEF25-75 in the Sidestream/ CR50 group compared to $39 \%$ of patients in the Hudson/ Pulmo-Aide group, after 1 week of treatment with rhDNase.

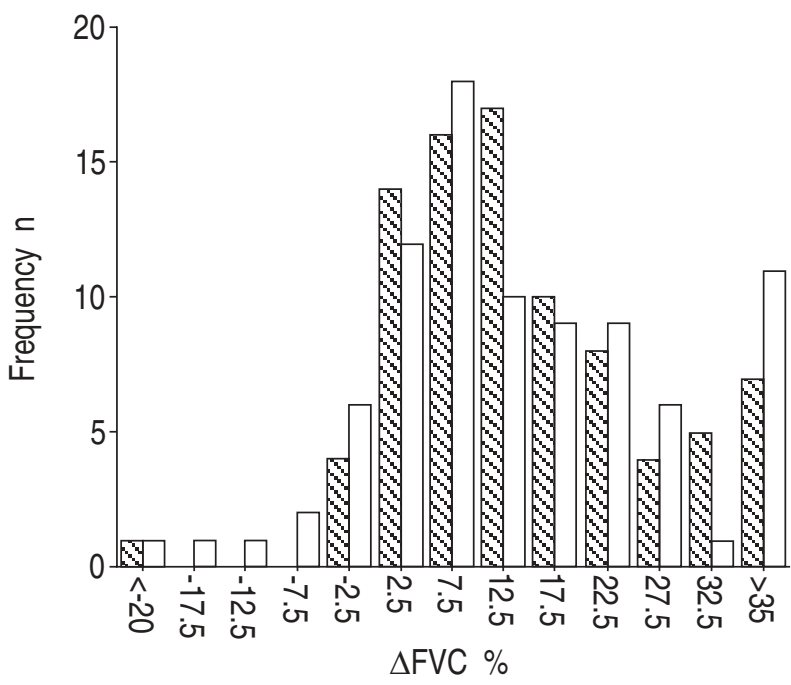

Fig. 2. - Histogram of percentage change from baseline in forced vital capacity $(\triangle \mathrm{FVC})$ for the Sidestream/CR50 aerosol delivery system ( $\$$ ) and the Hudson/Pulmo-Aide system ( $\square$ ).

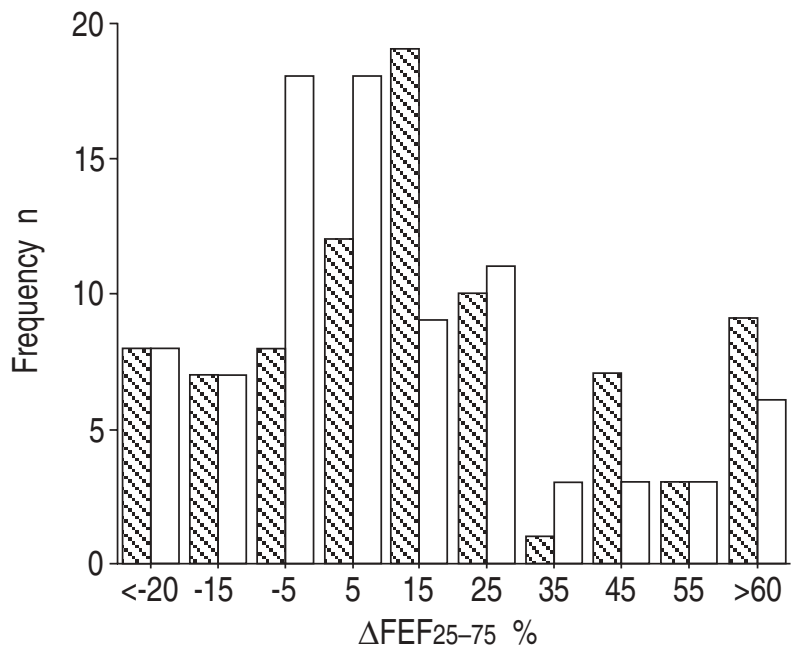

Fig. 3. - Histogram of percentage change from baseline in forced expiratory flow at $25-75 \%$ of expiration $(\triangle \mathrm{FEF} 25-75)$ for the Sidestream/CR50 aerosol delivery system ( $\mathrm{B}$ ) and the Hudson/PulmoAide system $(\square)$.

\section{In vitro study}

The dynamic pressure and flow characteristics for the two aerosol delivery systems were significantly different $(\mathrm{p}<0.05)$ and are summarized in table 5. The sidestream/ CR50 combination reduced nebulization time compared to the Hudson/Pulmo-Aide system (4.8 compared to 8.4 min, respectively). The distribution in particle size of the aerosol mass produced by the two delivery systems is presented in figure 4 . The mass median diameter (interquartile range) for the Sidestream/CR50 system was 3.42 (3.3-3.8) $\mu \mathrm{m}$ compared to 6.87 (6.1-7.4) $\mu \mathrm{m}$ for the Hudson/Pulmo-Aide system $(\mathrm{p}<0.001)$. The respirable fraction, defined as percentage of particles in the 1.2-5.6 $\mu \mathrm{m}$ range was $70(68-75) \%$ for the Sidestream/CR50 combination and 35 (33-42)\% for the Hudson/PulmoAide system $(\mathrm{p}<0.001)$. The percentage of particles less than $1.2 \mu \mathrm{m}$ in size was also greater for the Sidestream/ CR50 system (16\%) compared to the Hudson/PulmoAide combination (4\%). Estimates of mass conservation show that up to $90 \%$ of the theoretical total drug mass was recovered. Nebulizer efficiency was similar in the two groups, but a greater percentage of drug was delivered in the respirable range by the Sidestream/CR50 combination (33\%) compared to the Hudson/Pulmo-Aide system $(16 \%)$.

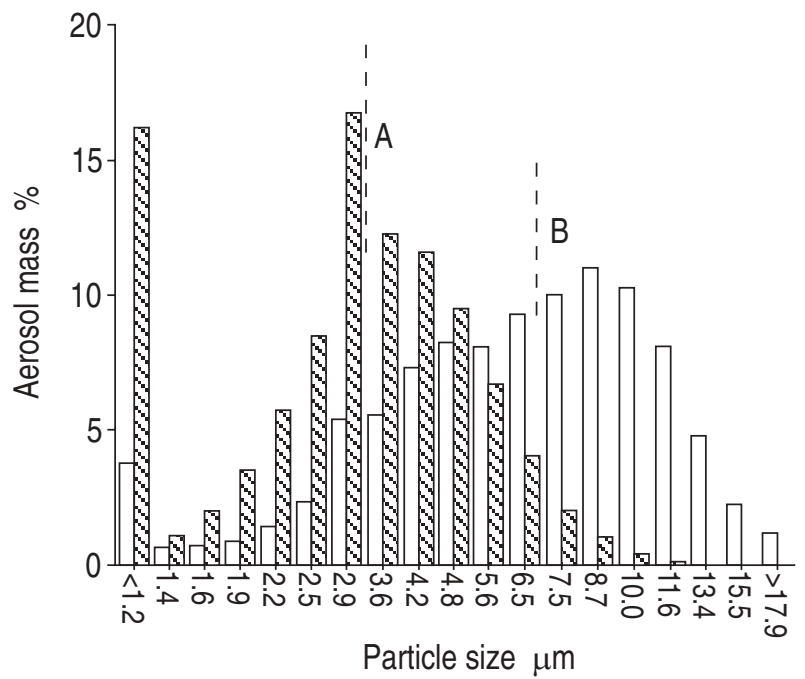

Fig. 4. - Distribution in particle size of the aerosol mass produced by the Sidestream/CR50 aerosol delivery system ( 3 ) and the Hudson/Pulmo-Aide system ( $\square$ ). A: mass median diameter of $3.42 \mu \mathrm{m}$ for aerosol mass produced by Sidestream/CR50; and B: mass median diameter of $6.87 \mu \mathrm{m}$ for aerosol mass produced by Hudson/PulmoAide.

Table 5. - In vitro characteristics of the aerosol delivery systems

\begin{tabular}{lccccccc}
\hline & $\begin{array}{c}\text { Pressure } \\
\mathrm{kPa}\end{array}$ & $\begin{array}{c}\text { Flow } \\
\mathrm{L} \cdot \mathrm{min}^{-1}\end{array}$ & $\begin{array}{c}\text { Nebulization } \\
\text { time } \\
\mathrm{min}\end{array}$ & $\begin{array}{c}\text { MMD } \\
\mu \mathrm{m}\end{array}$ & $\begin{array}{c}\text { Respirable } \\
\text { fraction } \\
\%\end{array}$ & $\begin{array}{c}\text { Nebulizer } \\
\text { efficiency } \\
\%\end{array}$ & $\begin{array}{c}\text { Aerosol } \\
\text { output } \\
\%\end{array}$ \\
\hline Sidestream/CR50 & 17.25 & 6.5 & 4.8 & 3.42 & 71 & 46 & 33 \\
& $(15.2-17.2)$ & $(6.4-6.6)$ & $(4.7-4.9)$ & $(3.3-3.8)$ & $(68-75)$ & $(44-49)$ & $(30-37)$ \\
Hudson/Pulmo-Aide & 12.42 & 6.3 & 8.4 & 6.87 & 35 & 44 & 16 \\
& $(11.0-12.4)$ & $(6.2-6.4)$ & $(8.2-10.0)$ & $(6.1-7.4)$ & $(33-42)$ & $(41-49)$ & $(14-20)$ \\
p-value $^{\#}$ & $<0.01$ & $<0.05$ & $<0.05$ & $<0.001$ & $<0.001$ & NS & $<0.005$ \\
\hline
\end{tabular}

Values are presented as median, and interquartile range in parenthesis. \#: significance between the two groups as evaluated by the Mann-Whitney U-test. MMD: mass median diameter; Aerosol output: percentage of total nebulizer output in the respirable range; NS: nonsignificant. 


\section{Discussion}

The changes in pulmonary function following treatment with rhDNase demonstrate that the Sidestream nebulizer was at least as effective as the Hudson nebulizer. The median changes for FEV1 and FEF25-75 were $5 \%$ greater with the Sidestream nebulizer than the Hudson nebulizer. A higher proportion of patients in the Sidestream group had a $>10 \%$ improvement in FEV1, FVC and FEF25-75 compared to the Hudson nebulizer group. However, these changes were not statistically significant as the statistical power of the study was inadequate to evaluate this change.

The results suggest that the Sidestream/CR50 aerosol delivery system is more efficient than the Hudson/ Pulmo-Aide combination. The nebulization rates and the respirable fraction of the aerosol mass generated were greater for the Sidestream/CR50 combination, whilst the mass median diameter was lower. However, dynamic processes, such as evaporation, aggregation and sedimentation, occur, so that the particle size distribution entering the lung is unlikely to resemble the particle size distribution from the outlet of the nebulizer. The estimated respirable output of the Sidestream/CR50 combination was double that of the Hudson/Pulmo-Aide system. However, the measurements performed in this study estimate the total aerosol output in the respirable range available to the patient. The aerosols are generated continuously throughout the breathing pattern but only delivered during the inhalation phase. No estimate of drug wastage during breathholding or expiration is made. The Venturi effect employed by the Sidestream nebulizer complicates this issue further because the additional entrained ambient air increases the flow rate output to $16 \mathrm{~L} \cdot \mathrm{min}^{-1}$. This may boost drug delivery during the initial stages of inspiration, but as the effect persists throughout the respiratory cycle a greater proportion of the aerosol would be wasted in expiration. This complicates the issue of nebulizer efficiency, and, therefore, the only satisfactory estimate of efficiency is patient response. In this study, the activity of the drug following the nebulization process was not evaluated in vitro, but other studies have shown that rhDNase retains its activity following aerosolization with either the Hudson/Pulmo-Aide or the Sidestream/CR50 delivery systems $[12,13]$.

The better in vitro results of the Sidestream/CR50 system may account for the greater improvements in pulmonary function compared with the Hudson/PulmoAide group. However, a simple increase in the amount of rhDNase delivered to the airways is unlikely to fully explain the changes in lung function. The earlier US Phase II study demonstrated a similar degree of improvement in lung function both for the $2.5 \mathrm{mg}$ (13.8\% change in FEV1) and the $10 \mathrm{mg}$ dose of rhDNase (14.5\% change in FEV1) after 10 days of therapy [5]. Differences in particle distribution may account for some of the differences in clinical efficacy observed in the present study. In CF airways, obstruction and excessive airway secretions may cause local turbulence and eddy formation, resulting in the deposition of particles on the walls of the major airways [14]. It is possible that the greater proportion of particles in the respirable range and lower mass median diameter of the aerosol mass produced by the Sidestream/CR50 system allow greater penetration of rhDNase to the smaller airways, and, therefore, greater improvements in FEV1 and FEF25-75. Following our preliminary results, a large multicentre study was initiated in North America [15]. A total of 749 patients were randomized to receive $2.5 \mathrm{mg}$ rhDNase daily for 14 days delivered either by the Hudson/Pulmo-Aide combination or the Sidestream/MobilAire combination. However, in the North American study, patients had very mild obstructive lung disease (baseline FVC 97-99\% pred and baseline FEV1 87-89\% pred). Improvements in pulmonary function were, therefore, limited $(2.5 \%$ for the Hudson/Pulmo-Aide group and $4.3 \%$ for the Sidestream/MobilAire group; $\mathrm{p}=0.06$ ).

The results may have cost implications, as the annual cost of the Sidestream/CR50 combination is $£ 99.50$ (two reusable Sidestreams and CR50 compressor, Medic-Aid, January 1996) compared to $£ 541.15$ for the Hudson/ Pulmo-Aide combination (365 disposable Hudson nebulizer units at $£ 441.65$, Hudson, January 1996), and PulmoAide compressor at $£ 99.50$ (DeVilbiss, January 1996). However, this analysis does not take into account the common practice of reusing the disposable nebulizers by individual patients. In a recent survey, over $50 \%$ of subjects used the disposable units for more than 14 days [16]. Some centres have found that they may last for up to 4 months, provided they are cleaned and sterilized daily [17]. Nebulizer performance appears to be stable with repeated use, but the main problem is bacterial contamination. Staphylococcus aureus was cultured from 57\% and Pseudomonas aeruginosa from $37 \%$ of the nebulizers that were used repeatedly [16]. Further investigation is required to determine whether more efficient delivery systems allow dose reductions to be made, as this would reduce the current drug costs $(£ 7,469.81$ per annum, based on rhDNase $2.5 \mathrm{mg}$ once daily, Mimms, January 1996).

The Sidestream/CR50 combination is a quicker, more efficient, system in vitro and clinically an effective alternative to the Hudson/Pulmo-Aide system for the aerosolization of recombinant human deoxyribonuclease in cystic fibrosis.

Acknowledgement: The authors thank J. Turner (medical statistician) for assistance with statistics.

\section{References}

1. Boat TF. Cystic fibrosis. In: Murray JF, Nadel JA, eds. Textbook of Respiratory Medicine. Vol. 1. Philadelphia, W.B. Saunders, 1988; pp. 1126-1152.

2. Lethem MI, James SL, Marriott C, Burke JF. The origin of DNA associated with mucus glycoproteins in cystic fibrosis sputum. Eur Respir J 1990; 3: 19-23.

3. Chernick WS, Barbero GJ. Composition of tracheobronchial secretions in cystic fibrosis of the pancreas and bronchiectasis. Pediatrics 1959; 24: 739-745.

4. Lethem MI, James SL, Marriott C. The role of mucous glycoproteins in the rheologic properties of cystic fibrosis sputum. Am Rev Respir Dis 1990; 142: 1053-1058.

5. Ramsey BW, Astley SJ, Aitken ML, et al. Efficacy and safety of short-term administration of aerosolised recombinant human deoxyribonuclease in patients with cystic fibrosis. Am Rev Respir Dis 1993; 148: 145-151. 
6. Ranasinha C, Assoufi B, Shak S, et al. Efficacy and safety of short-term administration of aerosolised recombinant human DNase I in adults with stable stage cystic fibrosis. Lancet 1993; 342: 199-202.

7. Fuchs HJ, Borowitz DS, Christiansen DH, et al. Effect of aerosolised recombinant human DNase on exacerbations of respiratory symptoms and on pulmonary function in patients with cystic fibrosis. N Engl J Med 1994; 331: 637-642.

8. Shah PL, Scott SF, Geddes DM, Hodson ME. Two years experience with recombinant human DNase in the treatment of cystic fibrosis. Respir Med 1995; 89: 499502.

9. Byron PR. Aerosol formulation, generation, and delivery using nonmetered systems. In: Byron PR, ed. Respiratory Drug Delivery. Boca Raton FL, CRC Press, 1990; Chap. 6.

10. Horbett TA. Adsorption of proteins and peptides at interfaces. In: Ahern TC, Manning MC, eds. Stability of Protein Pharmaceuticals. Part A. Chemical and Physical Pathways of Degradation. New York, Plenium Press, 1992; pp. 195-210.

11. American Thoracic Society. Standardisation of spiro- metry: 1994 update. Am J Respir Crit Care Med 1995; 152: $1107-1136$.

12. Cipolla D, Gonda I, Shire SJ. Characterization of aerosol of recombinant deoxyribonuclease I (rhDNase) generated by jet nebulisers. Pharmacol Res 1994; 11: 491-498.

13. Hung JCC, Hambleton G, Super M. Jet nebulising systems for recombinant human DNase I. Arch Dis Child 1994; 71: 558-559.

14. Anderson PJ, Blanchard JD, Brain JD, Feldman HA, McNamara JJ, Heyden J. Effect of cystic fibrosis on inhaled aerosol boluses. Am Rev Respir Dis 1989; 140: 1317-1324.

15. Geller D, Eigen H, Fiel S, Lamarre A, Konstan M, Johnson C. Aerosolised dornase alfa in cystic fibrosis: smaller particle size may improve outcome in patients with mild obstructive lung disease (Abstract 266). Pediatr Pulmonol 1996; Suppl. 13: 283.

16. Joy P, Rosenfield M, Emerson J, et al. Home nebuliser usage among CF patients (Abstract 363). Pediatr Pulmonol 1996; Suppl. 13: 309.

17. Newman SP, Clarke SW. Therapeutic aerosols. 1. Physical and practical considerations. Thorax 1983; 38: 881-886. 